\title{
Ultrasound supported flocculation of borate tailings with differently charged flocculants
}

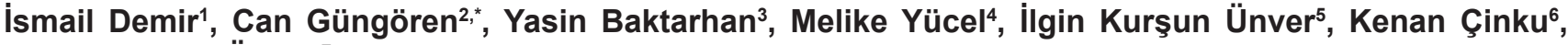 \\ Şafak Gökhan Özkan \\ ${ }^{1}$ İstanbul University-Cerrahpaşa, Engineering Faculty, Mining Engineering Department, Büyükçekmece, Istanbul, 34500, Turkey \\ ORCID orcid.org/0000-0003-0949-7706 \\ 2 İstanbul University-Cerrahpaşa, Engineering Faculty, Mining Engineering Department, Büyükçekmece, Istanbul, 34500, Turkey \\ ORCID orcid.org/0000-0002-6664-1551 \\ ${ }_{3}^{3}$ İstanbul University-Cerrahpaşa, Engineering Faculty, Mining Engineering Department, Büyükçekmece, Istanbul, 34500, Turkey \\ ORCID orcid.org/0000-0001-7547-0785 \\ ${ }^{4}$ İstanbul University-Cerrahpaşa, Engineering Faculty, Mining Engineering Department, Büyükçekmece, Istanbul, 34500, Turkey \\ ORCID orcid.org/0000-0003-1731-4041 \\ 5 İstanbul University-Cerrahpaşa, Engineering Faculty, Mining Engineering Department, Büyükçekmece, Istanbul, 34500, Turkey \\ ORCID orcid.org/0000-0001-7348-6054 \\ ${ }_{6}^{6}$ İstanbul University-Cerrahpaşa, Engineering Faculty, Mining Engineering Department, Büyükçekmece, Istanbul, 34500, Turkey \\ ORCID orcid.org/0000-0001-7523-8126 \\ ${ }^{7}$ Turkish-German University, The Institute of the Graduate Studies in Science and Engineering, Department of Robotics and \\ Intelligent Systems, Beykoz, İstanbul, 34820, Turkey \\ ORCID orcid.org/0000-0002-7770-7480
}

\section{ARTICLE INFO}

\section{Article history:}

Received July 17, 2021

Accepted August 22, 2021

Available online September 30, 2021

Research Article

DOI: 10.30728/boron.971892

\section{Keywords:}

Boron tailings

Flocculation

Settling rate

Turbidity

Ultrasound

\begin{abstract}
Mining activities are followed by mineral processing and wet beneficiation methods which generate a significant amount of tailings. Slime fractions are discharged to the tailing ponds with associated process water and this causes storage and disposal difficulties and creates severe environmental problems. Therefore, dewatering these tailings is necessary for both economic and environmental aspects. In this study, the flocculation behaviors of the boron tailings from Ağıldere and Hisarcık (Turkey) were studied in the presence of anionic, cationic, and nonionic flocculants. The results showed that the free settling condition was optimum for the Ağıldere sample. On the contrary, the settling rate of the Hisarcık sample increased considerably by the use of flocculants with a significant decrease in the turbidity of the suspension. Flocculation experiments indicated that the effect of the flocculant type on the flocculation of the Hisarcık sample can be generally ordered as anionic>cationic>non-ionic >no-flocculant. Furthermore, ultrasound was used as a supporting application. The results indicated that although the ultrasound application decreased the settling rate of both samples, lower sediment bed heights were obtained for the Hisarcık sample with ultrasound because of the formation of a more compact sediment bed in the presence of ultrasound.
\end{abstract}

\section{Introduction}

Dewatering of suspensions is carried out by the separation of solids from a liquid by mechanical compression, air displacement under vacuum or pressure, and drainage in a gravitational or centrifugal system. When the products of these methods are considered, it can be seen that the solid/liquid separation usually needs a long time [1,2]. In order to accelerate and increase the efficiency of solid/liquid separation, long-chain polymers (flocculants) which adsorb to particle surfaces and form bridges between the finely dispersed particles can be employed [3-5]. The flocculation rate and efficiency dependent upon various parameters including the surface properties of the solid, the interac- tions between the flocculant and the particles, the water content of the suspension, and the dosage of the flocculant. Therefore, many optimization experiments should be carried out for these parameters including the various flocculant types [6,7].

As of the end of 2020 , Turkey has $73.6 \%$ of the total world reserves [8]. Turkey has the biggest boron reserve in the world and a significant amount of the production of boron minerals [9]. Some methods including flotation $[10,11]$, leaching [12], heat treatment [13], gravity separation [9], electrostatic separation [14] were tried for the beneficiation of boron minerals at a laboratory scale. However, the most economic and viable beneficiation method for boron minerals is 
known as the removal of clay content by washing after mechanical attrition at the industrial scale $[11,15]$. As a result of the beneficiation processes, a significant amount of tailings are generated and the fine fractions typically less than $3 \mathrm{~mm}$ are discharged to the tailing ponds with associated process water, which causes important storage, disposal, and environmental problems [16]. Therefore, the dewatering of these tailings is very crucial in the economic and environmental aspects. However, only a few researchers studied the flocculation of boron ores and tailings. Çırak and Hoşten [2] emphasized that since the clay content of the boron tailings decreases the sedimentation rate, the sedimentation process in the tailing ponds can be increased up to ten days. In addition, it is reported that the treatment of borax tailings can be feasible if the parameters of the solid/liquid separation process are implemented properly [5].

The efficiency of mineral processing operations can be enhanced by ultrasound (US) applications [17]. Ultrasound is a soundwave above the human perception frequency limit (more than $20 \mathrm{kHz}$ ) [18]. The ultrasonic application causes acoustic streaming in a liquid medium [19]. In addition, ultrasound travels in a fluid as three-dimensional pressure waves consisting of alternating cycles of compression and rarefaction. If the negative pressure generated during the rarefaction cycle is sufficient to overcome the molecular forces binding the liquid, cavitation bubbles occurred [20]. These bubbles are collapsed in the immediate compressing phase with releasing a very large but localized burst of energy. This process is known as cavitation and some extremely high temperature $(5000 \mathrm{~K})$ and pressure (1000 atm) conditions can be obtained in the liquid medium via the cavitation process [21]. The level of cavitation is higher in the presence of solid particulate matter in the liquid. The cavitation bubbles formed at the solid surfaces can help the separation of solid and liquid via decreasing the surface energy.

Singh [22] used ultrasound in the solid/liquid separation of fine clean coal particles by vacuum filtration. His results indicated that ultrasound pretreatment has the potential for better cake moisture removal and enhanced filtration rate. Önal et al. [23] reported that the flocculant consumption is reduced with the use of ultrasound in the clay flocculation, decrease the settling time by half with an increased final pulp density. Burat et al. [24] investigated the effects of ultrasound on the dewatering of fine coal particles with a high frequency vibrating screen and they obtained a lower moisture content with ultrasound.
In this study, the flocculation behaviors of the tailings of two boron processing plants located in Ağıldere (Bandırma), and Hisarcık (Emet) were studied in the presence of differently charged (anionic, cationic, and non-ionic) flocculants and the effect of the use of ultrasound on the flocculation process was investigated.

\section{Materials and Methods}

\subsection{Materials}

Although boron is one of the rarest elements in the earth's crust (10 ppm) [25], there are also places where boron minerals are collected and economically exploited. These deposits are generally directly related to hydrothermal spring activity, closed basins and Cenozoic volcanism in arid climate conditions and occurs in a limited number of Neogene to Holocene non-marine evaporitic settings [26]. Hisarcık deposit was formed in Miocene lake environments contributed by volcanism [27].

The samples used in this study were obtained from the tailing ponds of two different boron processing plants, which produce various boron-containing compounds including boric acid, borax pentahydrate, borax decahydrate, dehydrated borax, disodium octaborate tetrahydrate, zinc borate, and amorphous boron oxide [28,29]. The representative samples were taken systematically from the different sites and depths of the tailing ponds. The plants are located in Ağıldere/ Bandirma and Hisarcık/Emet regions in Turkey. The samples were coded as "Ağıldere" and "Hisarcık", respectively related to the plants they were collected.

Although the composition of borate formations differs related to the deposit, they are generally found together with sandstone, tuff, marl, clay, conglomerate, and limestone [26]. The Hisarcık deposit is generally composed of colemanite, ulexite, hydroboracite, and meyerhofferite. Clays accompanying boron minerals are mainly composed of montmorillonite. There are also illite and chlorite present in the clay zone. In addition, there are plenty of zeolites in the tuffs [30]. Other accompanied minerals are calcite, dolomite, gypsum, celestine, realgar, orpiment, and sulfur [25].

The chemical analysis of the samples was carried out by the volumetric titration method and the results are given in Table 1.

The particle size analysis of the samples was carried out with a laser diffraction particle size analyzer (Mastersizer 3000, Malvern, UK) and the results are given

Table 1. Chemical analysis of the samples.

\begin{tabular}{lcccccccccc}
\hline & $\begin{array}{c}\mathrm{B}_{2} \mathrm{O}_{3} \\
(\%)\end{array}$ & $\begin{array}{c}\mathrm{Na}_{2} \mathrm{O} \\
(\%)\end{array}$ & $\begin{array}{c}\mathrm{SiO}_{2} \\
(\%)\end{array}$ & $\begin{array}{c}\mathrm{SrO} \\
(\%)\end{array}$ & $\begin{array}{c}\mathrm{SO}_{4} \\
(\%)\end{array}$ & $\begin{array}{c}\mathrm{MgO} \\
(\%)\end{array}$ & $\begin{array}{c}\mathrm{CaO}_{(\%)} \\
\mathrm{Fe}_{2} \mathrm{O}_{3} \\
\text { A \%̆ }\end{array}$ & $\begin{array}{c}\mathrm{Al}_{2} \mathrm{O}_{3} \\
(\%)\end{array}$ & $\begin{array}{c}\mathrm{As}_{2} \mathrm{O}_{3} \\
(\%)\end{array}$ \\
Hisarcık & 8.16 & 4.91 & 17.6 & 0.824 & 1.308 & 13.6 & 15.5 & 0.245 & 1.02 & 0.0038 \\
\hline
\end{tabular}


in Figure 1 , in addition to the $\mathrm{d}_{10}, \mathrm{~d}_{50}$, and $\mathrm{d}_{90}$ sizes seen in Table 2.

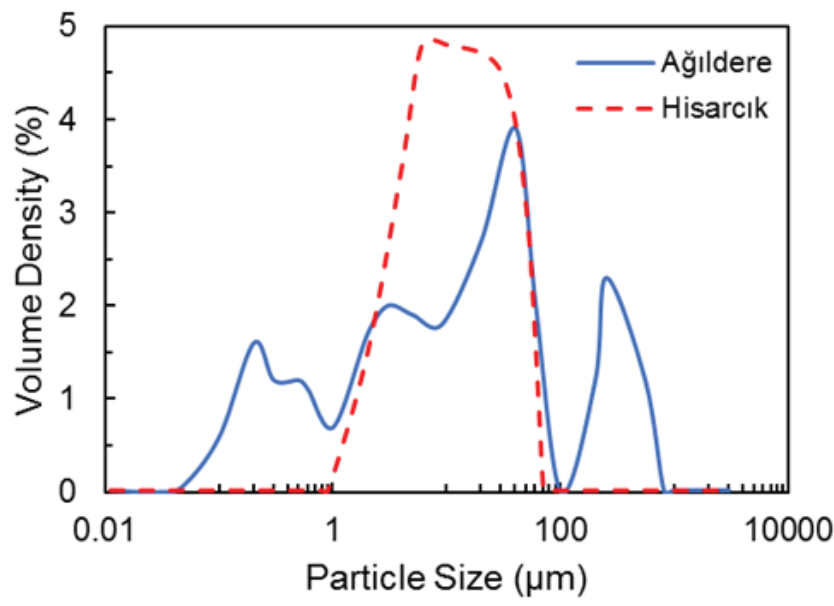

Figure 1. The particle size distribution of the samples.

Table 2. $d_{10}, d_{50}$, and $d_{90}$ sizes of the samples.

\begin{tabular}{lccc}
\hline & $\mathbf{d}_{10}$ & $\mathbf{d}_{50}$ & $\mathbf{d}_{90}$ \\
\hline Ağıldere $(\boldsymbol{\mu m})$ & 0.3 & 20.6 & 256.0 \\
Hisarcık $(\boldsymbol{\mu m})$ & 2.8 & 10.1 & 32.5 \\
\hline
\end{tabular}

It is seen in Figure 2 and Table 2 that the Ağıldere sample shows a wide particle size distribution with a $\mathrm{d}_{90}$ size of $256 \mu \mathrm{m}$. On the contrary, the Hisarcık sample was comprised of finer particles $\left(d_{90}=32.5 \mu \mathrm{m}\right)$. Furthermore, although the tailings have consisted of various minerals, the zeta potential was measured for the characterization of the surface electrical properties of the tailings. The measurements were done twice with the electrophoresis method using a zeta meter (Zeta Plus, Brookhaven, UK) without and with ultrasound, and the average of two measurements were calculated.

It is seen in Figure 2 that since the samples have differences in their chemical compositions as shown in Table 1, they have different behaviors at various $\mathrm{pH}$ conditions. The changes in the zeta potential in the presence of ultrasound should be originated from the removal of clay particles from the surfaces. It is also clear from Figure 2 that both of the tailings had no point of zero charges (pzc) and the zeta potentials were always negative.

The flocculants used in this study were obtained from NCC Chemical Co. (Turkey) with the commercial names of Newfloc-123 (anionic flocculant), NewFloc-8243 (cationic flocculant), and Newfloc-101 (non-ionic flocculant). The flocculant solutions were prepared using de-ionized (DI) water $(18.2 \mathrm{M} \Omega \cdot \mathrm{cm}$ at $25^{\circ} \mathrm{C}$ ) (Millipore Milli-Q, Merck, Germany), freshly. All experiments were performed at room temperature (23 $\left.\pm 1^{\circ} \mathrm{C}\right)$

\subsection{Methods}

First, the effect of the solid-in-pulp ratio on the settling properties of the samples was investigated with free settling experiments in the absence of flocculant. For this purpose, suspensions at $3 \%, 5 \%$, and $7 \%$ solid-inpulp ratios were prepared in a $1 \mathrm{dm}^{3}$ glass beaker and stirred using a flocculator (jar test device) (Velp Scientifica, Italy) at $200 \mathrm{rpm}$ for $10 \mathrm{~min}$. Since the success of the flocculation process is dependent upon the stirring speed and time [31,32] these values were kept constant in further experimental studies to investigate the effect of ultrasound on the flocculation process properly. In addition, in order to mimic the plant conditions, the flocculation experiments were carried out at the natural $\mathrm{pH}$ of the suspensions, which were $9.0 \pm 0.2$ for the Ağıldere and $9.7 \pm 0.1$ for the Hisarcık samples.

Then, the suspensions were transferred to a graduated cylinder, separately and the height of the sediment bed was recorded as a function of time up to $240 \mathrm{~min}$. The sediment bed heights as a function of settling time were used to obtain the settling rates.

Then, the effect of the flocculant type and dosage on the flocculation was studied using anionic, cationic,
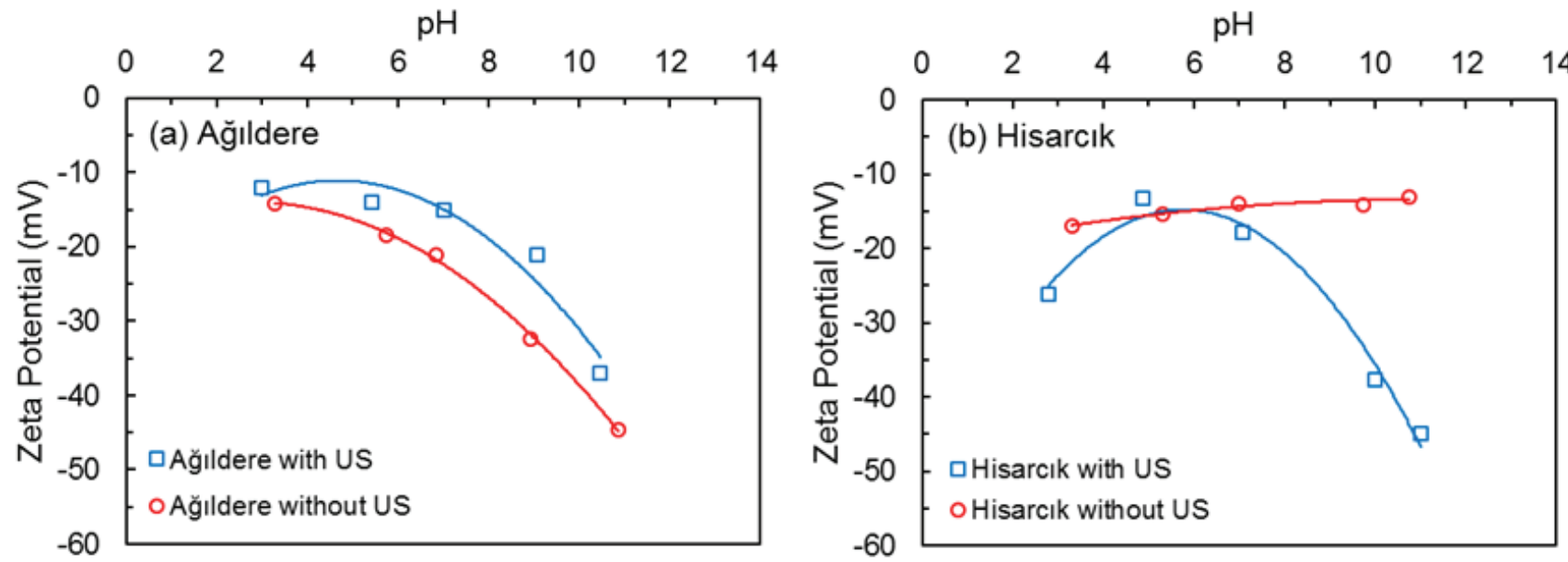

Figure 2. Zeta potential of Ağıldere (a) and Hisarcık samples (b). 
and non-ionic flocculants, separately. The flocculant solutions were prepared at $0.1 \%$ concentration by weight and used in the flocculation experiments in the volumes of $2 \mathrm{~cm}^{3}(67 \mathrm{~g} / \mathrm{t}), 4 \mathrm{~cm}^{3}(133 \mathrm{~g} / \mathrm{t})$, and $6 \mathrm{~cm}^{3}$ $(200 \mathrm{~g} / \mathrm{t})$.

The experiments with ultrasound were carried out using a cylindrical ultrasonic bath (Bandelin Sonorex RK 106, Germany) working at a constant frequency (35 $\mathrm{kHz}$ ) and power $(480 \mathrm{~W})$. In order to investigate the effect of ultrasound on the flocculation process and to observe whether the ultrasound was causing floc breakage, the ultrasonic application was performed for 10 min before the settlement process starts. The suspension was stirred with a glass bar gently during the ultrasonic application to prevent the suspension to settle. The mechanic stirring was not preferred to avoid further floc breakage. The ultrasonic application method is shown in Figure 3.

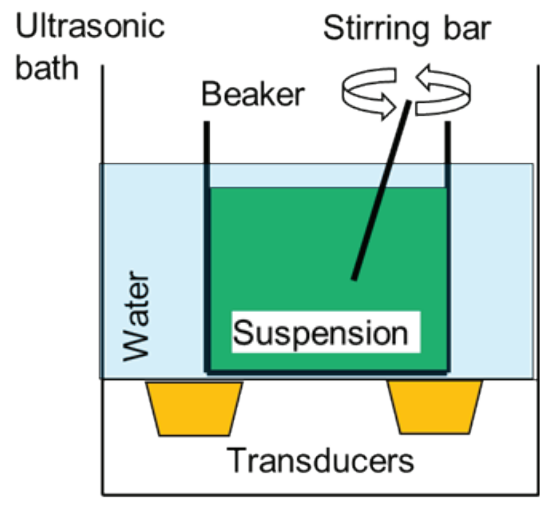

Figure 3. The ultrasonic application method.

During the flocculation experiments, a $5 \mathrm{~cm}^{3}$ sample was taken from the top of the suspension using a Pasteur pipette and the turbidity measurements were performed with a turbid meter (Aquafast-II, Thermo Scientific, USA) with respect to settling time.

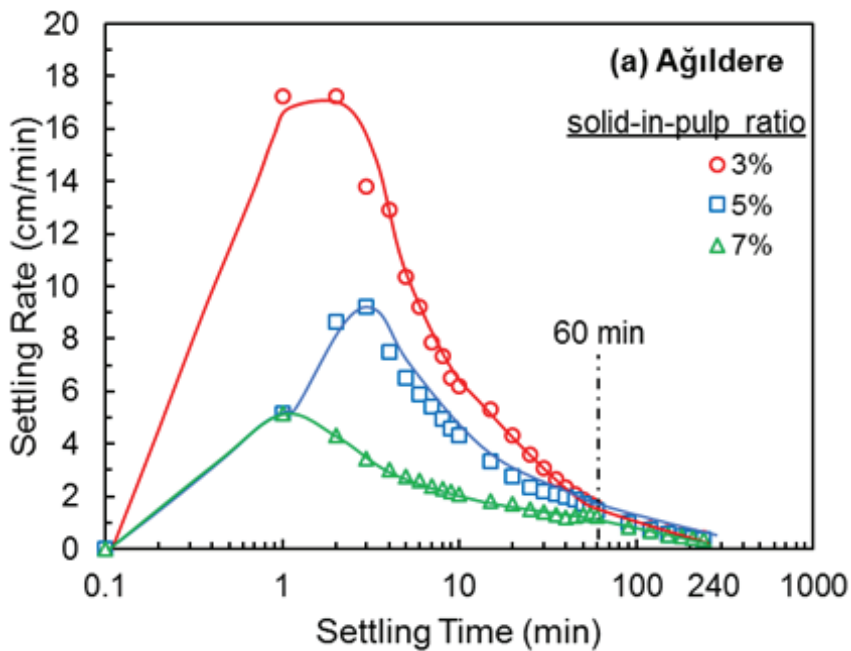

Figure 4. Settling rate of Ağıldere (a) and Hisarcık (b) samples at various solid-in-pulp ratios in the absence of flocculant.

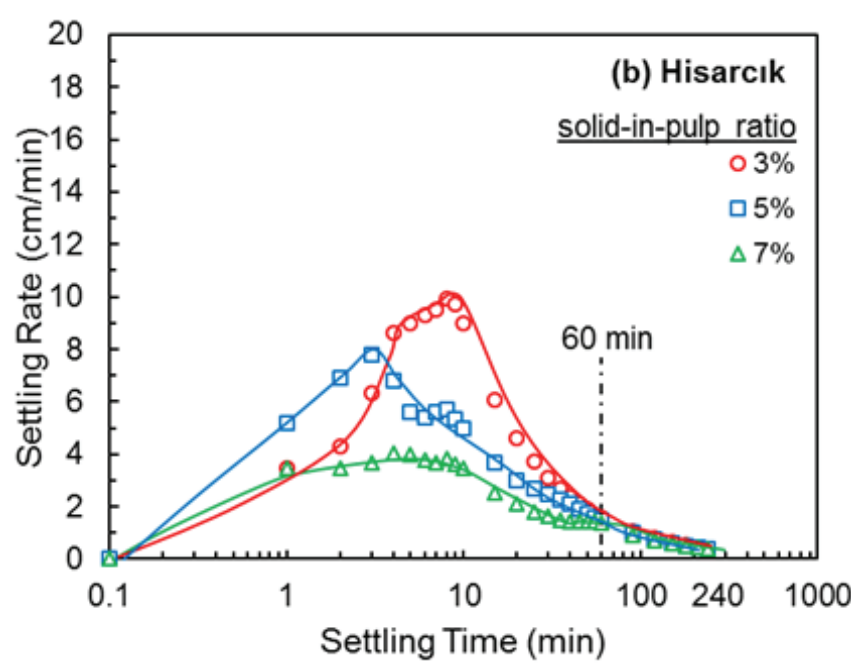

\section{Results and Discussion}

The settling rate [33] and the turbidity of the residual suspension $[34,35]$ are important indicators of the success of the flocculation process. The settling rate of the Ağıldere and Hisarcık samples at various solid-in pulp ratios is seen in Figure $4 a$ and $b$, respectively in the absence of flocculant. Figure 4 shows that the Ağıldere sample settled in a shorter time than the Hisarcık sample. While the maximum settling rate was observed between 1-3 min with the Ağıldere sample, the settling rate of the Hisarcık sample was the highest between 1-10 min. The maximum settling rate was obtained as $17 \mathrm{~cm} / \mathrm{min}$ at $1 \mathrm{~min}$ and $10 \mathrm{~cm} / \mathrm{min}$ at $8 \mathrm{~min}$ for Ağıldere and Hisarcık samples at 3\% solid-in-pulp ratio, respectively. Furthermore, it is obvious in Figure 4 that the flocculation process becomes more difficult with an increase in the solid-in-pulp ratio and therefore the settling rates decreased. This can be related to the increase in the clay content of the suspension and hence the change in its rheological properties [36]. It is known from the literature that the adsorbed flocculants per solid amount decreased with the increase in the solid-in-pulp ratio. In addition, the particle-reagent collision probability is low in crowded colloidal systems [37]. Therefore, it has an important role in flocculation efficiency $[38,39]$. However, it is also a fact that when the solid content of the system decreased, the flocculation capacity will also decrease. Therefore, no solidin-pulp ratios below $3 \%$ were used in this study considering the capacity of the flocculation process. It is also seen in Figure 4 that the settling rate did not change significantly after $60 \mathrm{~min}$ for both samples. Therefore, it was decided to perform flocculation experiments for up to $60 \mathrm{~min}$ for further studies.

The results of the flocculation experiments in the presence of flocculants along with the results of the turbidity measurements for the Ağıldere sample are seen in Figure 5. It is seen in Figure 5a-c that since the use of flocculant caused the re-stabilization of the particles

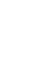


[40,41], flocculant addition decelerated the settling of the Ağıldere sample. For instance, at $1 \mathrm{~min}$ settling time, while the settling rate was $17 \mathrm{~cm} / \mathrm{min}$ without flocculant, it sharply decreased to $3 \mathrm{~cm} / \mathrm{min}$ with anionic flocculant at $67 \mathrm{~g} / \mathrm{t}$ while the settlement process did not begin in the presence of cationic and non-ionic flocculants. Although the settling rate increased with flocculant dosage, it is a fact that flocculants were not useful for the settlement of the Ağıldere sample. In parallel, the results of the turbidity measurements given in Figure 5(d-f) showed that more muddy suspensions were obtained at the end of $60 \mathrm{~min}$ settling time in the presence of flocculant. The difference in the turbidity of the suspension increased with flocculant dosage and reaches 617 NTU, 318 NTU, and 223 NTU, for anionic, non-ionic, and cationic flocculants at $200 \mathrm{~g} / \mathrm{t}$, respectively, while it was $171 \mathrm{NTU}$ in the absence of flocculant.

The results of the flocculation experiments in the presence of flocculants along with the results of the turbidity measurements for the Hisarcık sample are given in Figure 6.
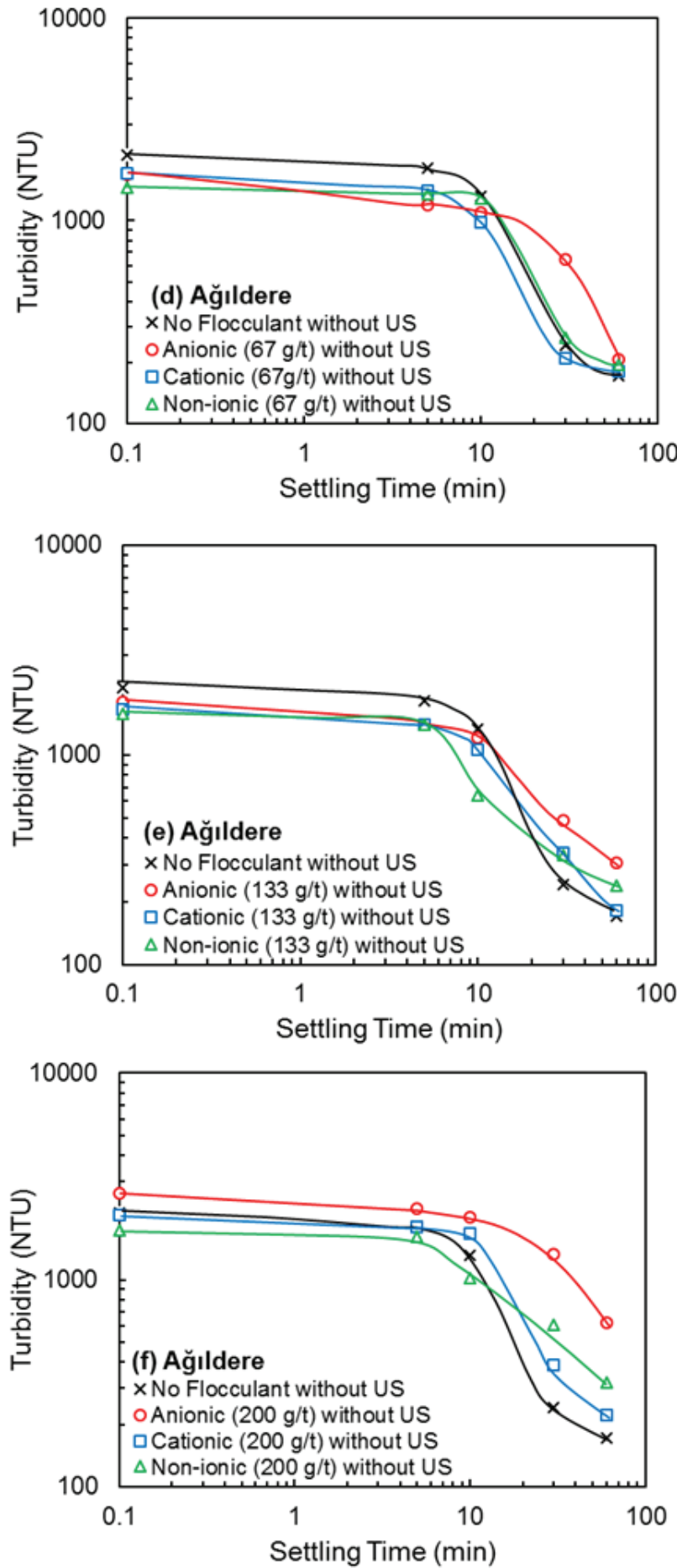

Figure 5. Settling rate $(a-c)$ and turbidity (d-f) of the Ağıldere sample related to flocculant type and dosage. 
Figure 6a-c indicates that contrary to the Ağıldere sample, the settling rate increased significantly in the presence of flocculant for the Hisarcık sample. While the settling rate was $3 \mathrm{~cm} / \mathrm{min}$ in the absence of flocculant, it increased to $52 \mathrm{~cm} / \mathrm{min}, 62 \mathrm{~cm} / \mathrm{min}$, and 69 $\mathrm{cm} / \mathrm{min}$ at $1 \mathrm{~min}$ in the presence of $67 \mathrm{~g} / \mathrm{t}$ non-ionic, cationic, and anionic flocculant, respectively. The maximum settling rate was obtained as $83 \mathrm{~cm} / \mathrm{min}$ at 200 $\mathrm{g} / \mathrm{t}$ anionic flocculant at $1 \mathrm{~min}$. It is also clear in Figure $6 \mathrm{~d}-\mathrm{f}$ that the use of flocculant decreased the turbidity of the suspension, considerably related to the flocculant type [42,43].
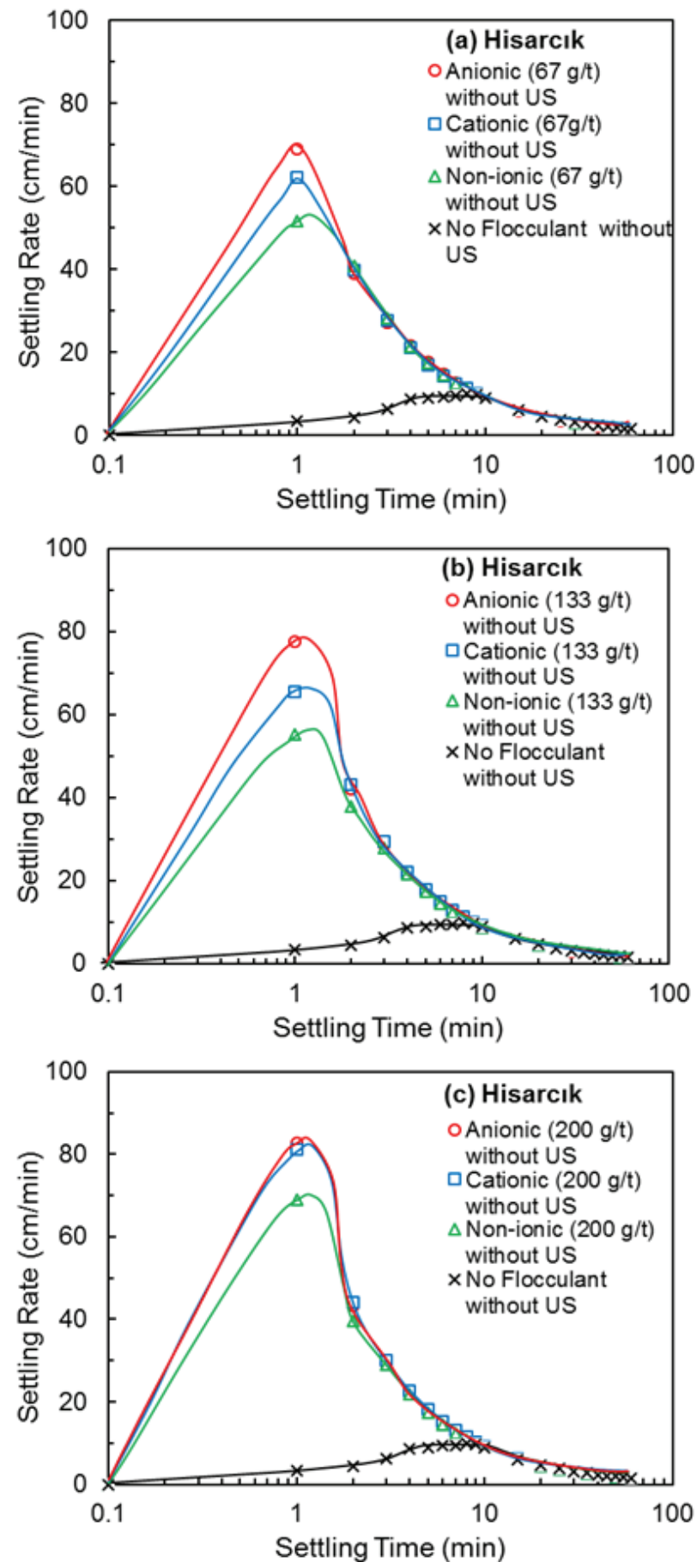

It is seen from the results of the flocculation experiments that the effect of the flocculant type on the flocculation of the Hisarcık sample can be generally written as anionic > cationic > non-ionic > no-flocculant. Considering that the tailings had negative zeta potentials, it can be said that the interaction between the particle surfaces and flocculant molecules was chemical rather than physical.

In the light of the flocculation experiments at various dosages, the ultrasound application was applied at 67 $\mathrm{g} / \mathrm{t}$ flocculant consideration considering the efficiency
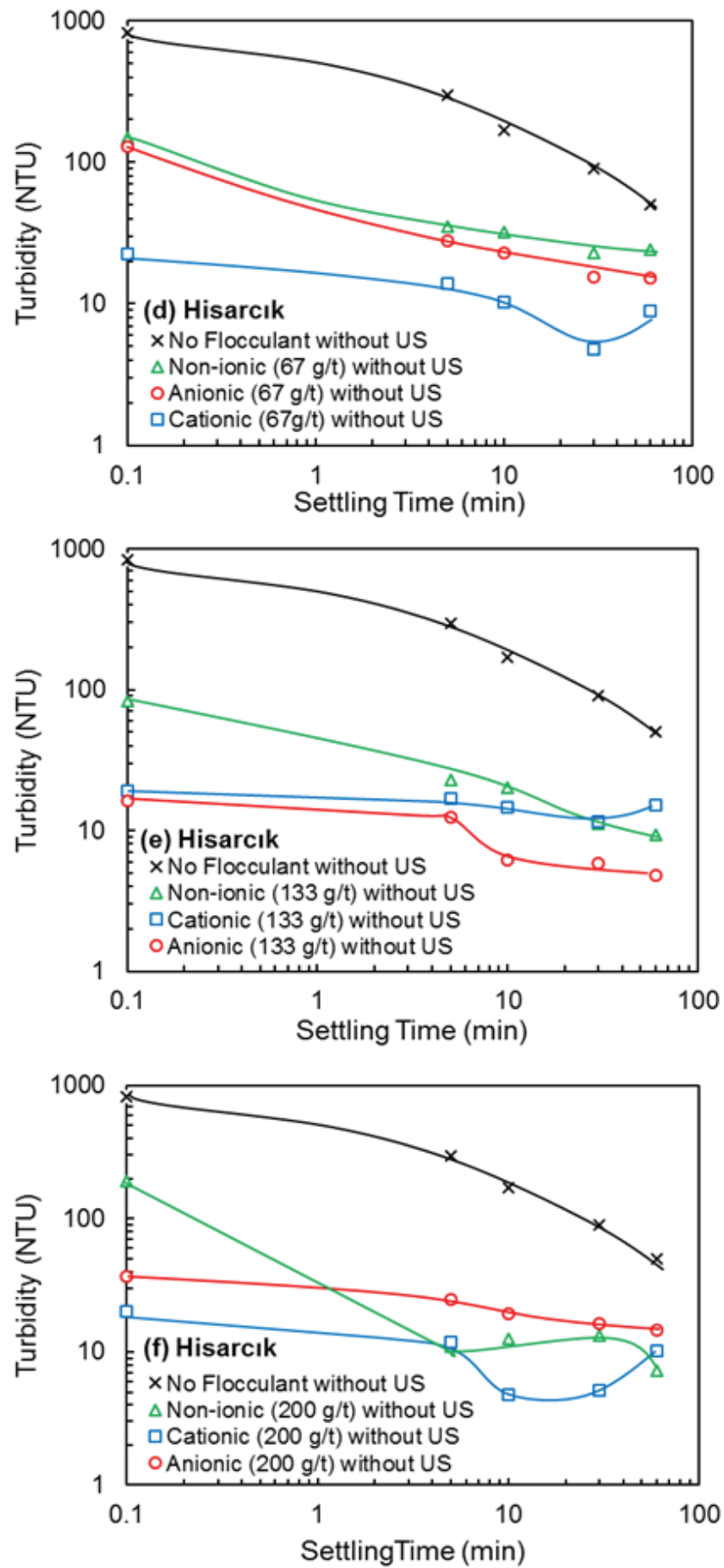

Figure 6. Settling rate $(a-c)$ and turbidity (d-f) of the Hisarcık sample related to flocculant type and dosage. 
and cost factors. The effect of the ultrasound application on the results of the settling rate and turbidity is given in Figure 7 for the Ağıldere sample. It is seen in Figure 7a-d that the use of ultrasound decreased the settling rate of the Ağıldere sample, significantly because of the floc breakage. For instance, while the settling rate was $17 \%$ at 1 min settling time in the absence of flocculant without ultrasound, it decreased to $2 \%$ with ultrasound. This trend did not change in the presence of flocculant. In several previous studies, it was also reported that ultrasound could be detrimental to the flocculation process related to the application conditions [44-46]. On the other hand, it is seen in Figure $7 \mathrm{e}-\mathrm{h}$ that lower turbidity values were obtained with ultrasound in most experiments because of the formation of a more compact sediment bed in the presence of ultrasound.

The results of the settling rate and turbidity measurements without and with ultrasound for the Hisarcık
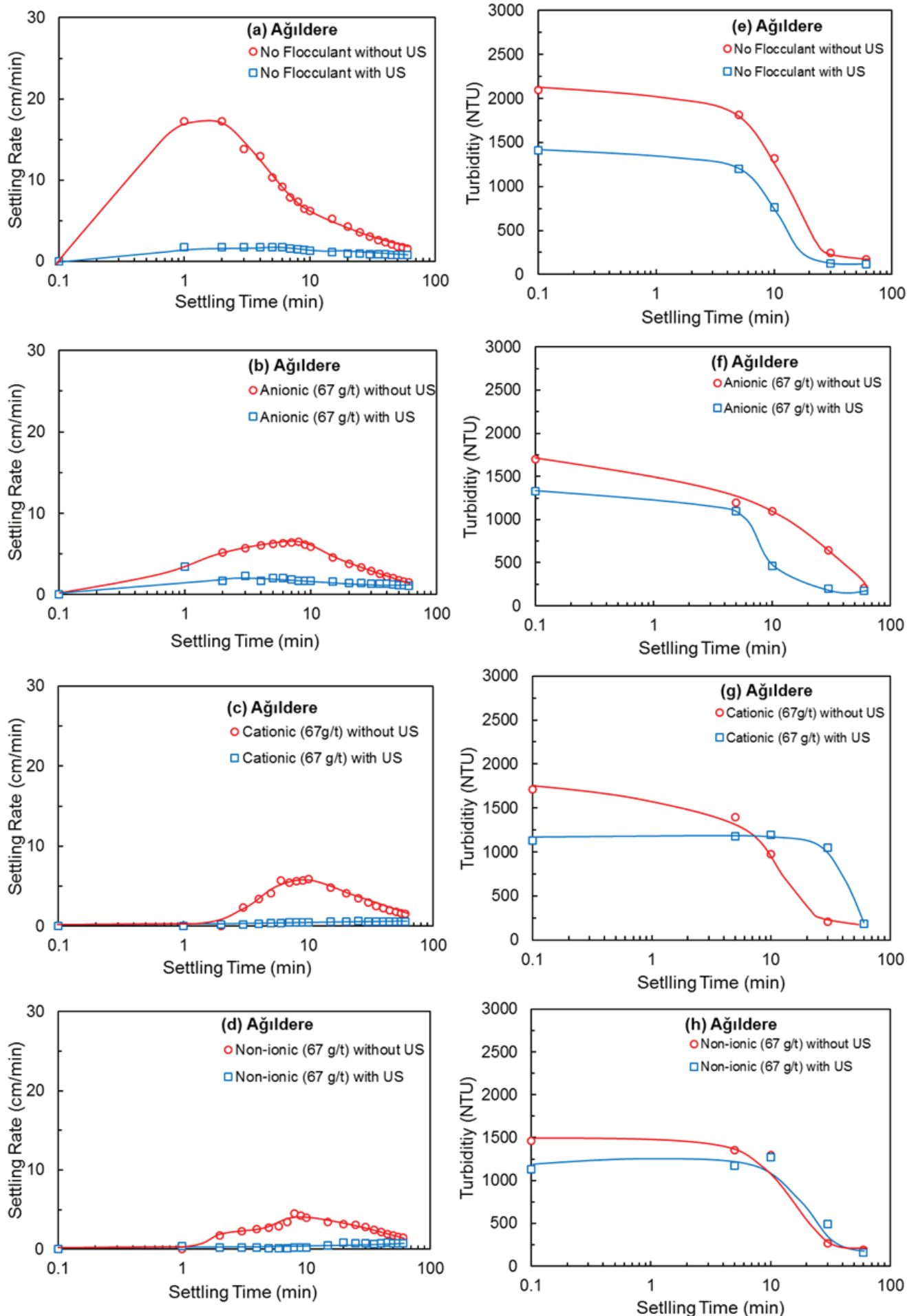

Figure 7. Settling rate (a-d) and turbidity (e-h) of the Ağıldere sample related to flocculant type without and with ultrasound. 
sample are given in Figure 8. Similar to the Ağıldere sample, the results of the experiments for the Hisarclk sample seen in Figure 8 show that lower settling rate values were obtained with ultrasound at shorter settling times. At longer settling times, the settling rates became equal without and with ultrasound. However, higher turbidity values were obtained with ultrasound. Although the use of flocculant increased the settling rate, the trend between the samples without and with ultrasound did not change. For instance, while the settling rate was $69 \mathrm{~cm} / \mathrm{min}$ without ultrasound, it was only $14 \mathrm{~cm} / \mathrm{min}$ with ultrasound in the presence of 67 $\mathrm{g} / \mathrm{t}$ anionic flocculant.

Height of the sediment bed of Ağıldere and Hisarcık samples without and with ultrasound at $60 \mathrm{~min}$ is given
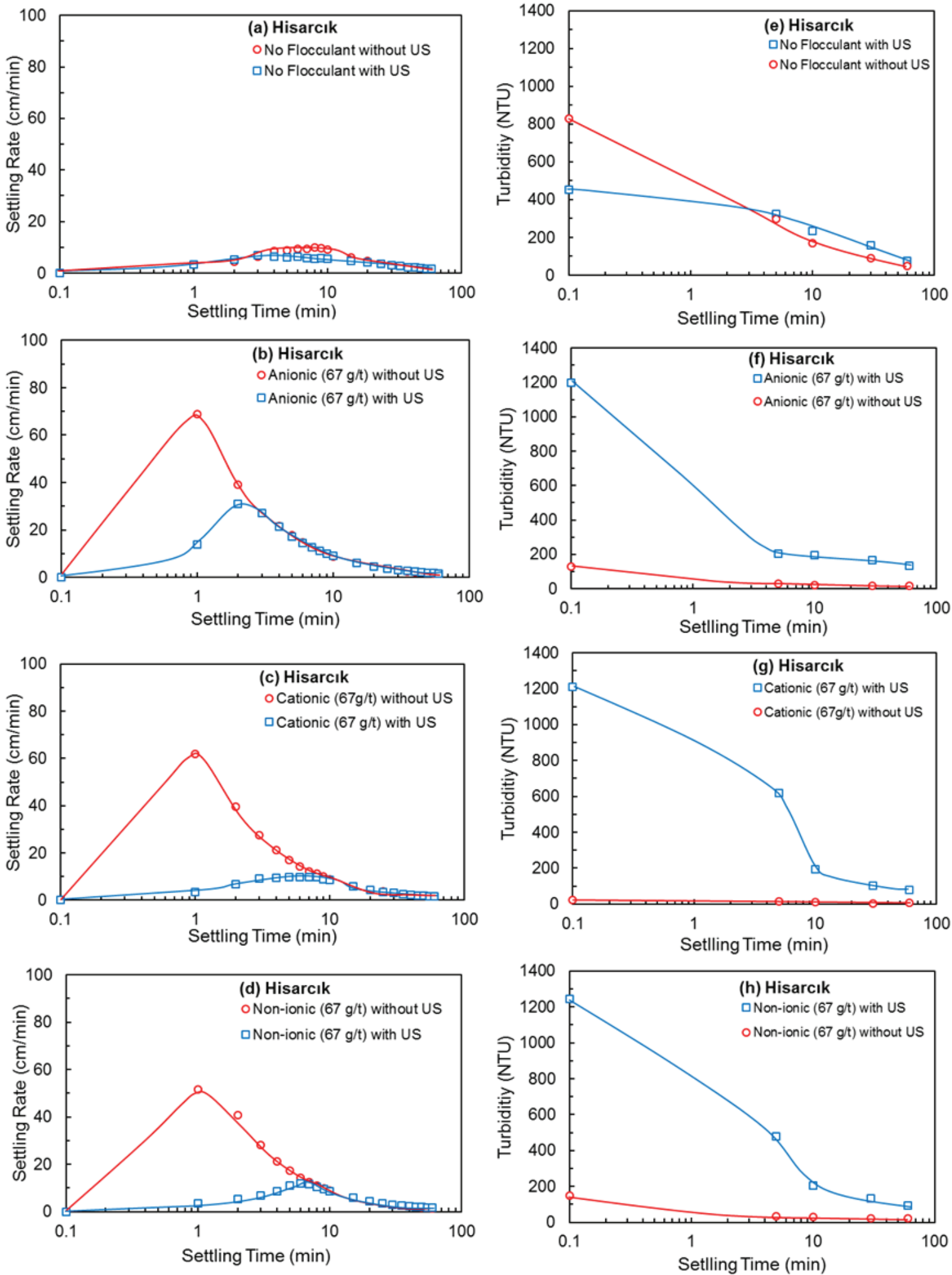

Figure 8. Settling rate (a-d) and turbidity (e-h) of the Hisarcık sample related to flocculant type without and with ultrasound. 
in Figure 9. Figure 9a shows that while higher sediment bed heights were obtained with ultrasound with the Ağıldere sample, ultrasound decreased the sediment bed heights of the Hisarcık sample as seen in Figure $9 b$. The positive effect of ultrasound on the sediment bed height was mostly originated from allowing closer packing of the particles [47]. Meanwhile, there are some additional effects of ultrasound including the enhancement of emulsification and dispersion processes $[17,48]$, as well as increasing the polymer adsorption onto clay particles [49], facilitation of the migration of moisture through channels created by wave propagation [24]. Furthermore, the cavitation bubbles formed at the solid surfaces can help the separation of solid and liquid via forming gas/liquid interfaces with much lower surface energy compared to solid/liquid surfaces [23]. Furthermore, Videla et al. [50] stated that ultrasound can favor the effects of flocculants and increasing their performance. They compared the longitudinal and transverse ultrasonic radiation in flocculation. They stated that acoustic longitudinal radiation served better than transverse radiation to improve the sedimentation rate. Furthermore, they investigate the effect of frequency. Their results showed that the sedimentation rate improved as the frequency decreased, and therefore, ultrasound at different frequencies could be used in the flocculation process for optimization purposes. On the other hand, the detrimental effects of ultrasound on the flocculation of boron tailings observed in this study could be related to the floc breakage and inefficient agglomeration process in the presence of ultrasound in accordance with Riera-Franco de Sarabia et al. [51]. Moreover, it is also a fact that cavitation bubbles collapse asymmetrically in the presence of solid particles because of the asymmetric distribution of the pressure around the bubble near a solid particle. The asymmetric collapse of the cavitation bubbles causes the formation of micro-jets and shock waves
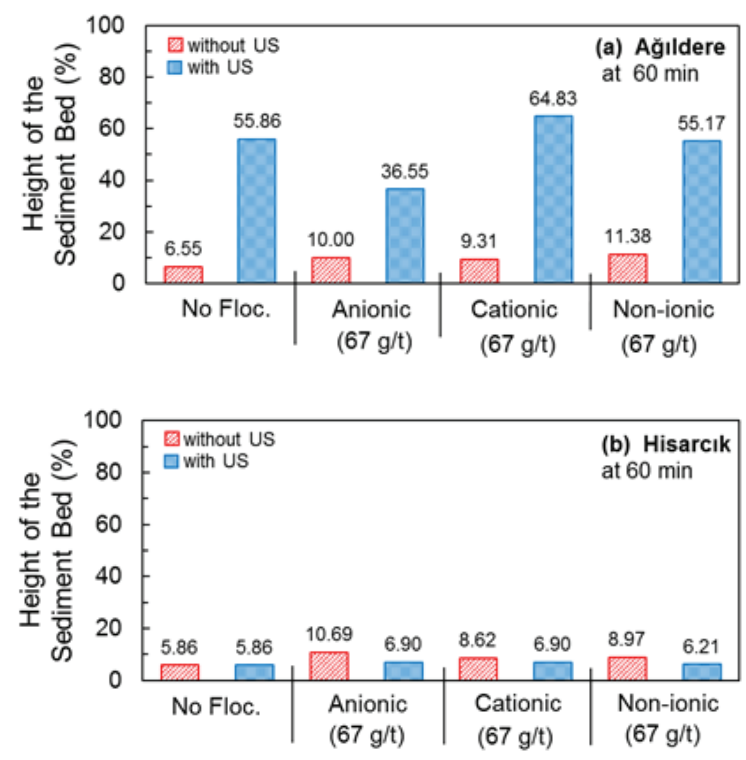

Figure 9. Height of the sediment bed for Ağıldere (a) and Hisarcık (b) samples.
$[21,52,53]$. These shock waves could remove the clay minerals on boron particles which are very fine and very difficult to settle. These fine clay particles could be responsible for the decrease in the settling rate and increase in the turbidity of the suspension.

\section{Conclusions}

In this study, the effect of ultrasound on the flocculation of the boron tailings from Ağıldere and Hisarcık regions of Turkey in the presence of anionic, cationic, and non-ionic flocculants was investigated in detail. The results showed that the decrease in the solid-in-pulp ratio increased the settling rate of both samples. It was observed that the Ağıldere sample could be settled in free settling conditions and flocculant addition harmed the settling process. On the other hand, there was a significant increase in the settling rate of the Hisarcık sample in the presence of flocculants with a considerable decrease in the turbidity of the suspension. The difference between the flocculation behaviors of the two samples was originated from the differences in their chemical compositions. The most effective flocculant types for the Hisarcık sample can be ordered as anionic, cationic, and non-ionic, respectively. In this study, ultrasound was also used as a supporting application for flocculation. The results indicated that although the use of ultrasound had a negative effect on the settling rate of both samples mostly caused by the floc breakage, since ultrasound allowed closer packing of the particles, lower sediment bed heights were obtained for the Hisarcık sample in the presence of ultrasound application.

\section{Acknowledgements}

This study was supported by the Research Fund of İstanbul University, project number: FBA-2017-25533.

\section{References}

[1] Çırak, M. (2010). Flocculation behavior of two different clay samples from Kirka tincal deposit [M. Sc. Thesis, Middle East Technical University]. Council of Higher Education Thesis Center (Thesis Number 269092).

[2] Çırak, M., \& Hoşten, Ç. (2015). Characterization of clay rock samples of a borax ore in relation to their problematical flocculation behavior. Powder Technology, 284, 452-458.

[3] Yang, Y., Wu, A., Klein, B., \& Wang, H. (2019). Effect of primary flocculant type on a two-step flocculation process on iron ore fine tailings under alkaline environment. Minerals Engineering, 132, 14-21.

[4] Ding, C., Xie, A., Yan, Z., Li, X., Zhang, H., Tang, N., \& Wang, X. (2021). Treatment of water-based ink wastewater by a novel magnetic flocculant of boron-containing polysilicic acid ferric and zinc sulfate. Journal of Water Process Engineering, 40.

[5] Çırak, M., \& Hoşten, Ç. (2017). Optimization of coagulation-flocculation process for treatment of a colloidal suspension containing dolomite/clay/borax. Interna- 
tional Journal of Mineral Processing, 159, 30-41.

[6] Şimşek, B., Taş, E., \& Sabah, E. (2019). Modeling and optimization of the flocculation process of polydisperse travertine suspension employing an eco-friendly hybrid flocculant. Arabian Journal of Geosciences, 12(24), 1-11.

[7] Sabah, E., \& Yeşilkaya, L. (2000). Evaluation of the settling behaviour of Kirka borax concentrator tailings using different type of polymers. Ore Dressing, 2000(3), 1-12.

[8] Eti Mine. (2021). Bor Sektör Raporu [Boron Sector Report]. The Ministry of Energy and Natural Resources. https://www.etimaden.gov.tr/storage/2021/Bor_Sektor_Raporu_2020.pdf

[9] Savaş, M. (2016). Recovery of colemanite from tailing using a Knelson concentrator. Physicochemical Problems of Mineral Processing, 52(2), 1036-1047.

[10] Özkan, Ş. G., \& Acar, A. (2004). Investigation of impact of water type on borate ore flotation. Water Research, 38(7), 1773-1778.

[11] Özdemir, O., \& Çelik, M. S. (2010). Surface Properties and Flotation Characteristics of Boron Minerals. The Open Mineral Processing Journal, 3(1), 2-13.

[12] Arslan, V., \& Bayat, O. (2016). Kolemanit cevherinden oksalik asit liçi ile borik asit eldesi [Production of boric acid from colemanite ore by oxalic acid leaching]. Journal of Underground Resources, 5(10), 11-20.

[13] Çelik, M. S., Batar, T., Akın, Y., \& Arslan, F. (1998). Upgrading schemes for boron minerals through calcination. Mining, Metallurgy \& Exploration, 15(1), 53-56.

[14] Eskibalcı, M. F., \& Özkan, Ş. G. (2012). An investigation of effect of microwave energy on electrostatic separation of colemanite and ulexite. Minerals Engineering, 31, 90-97.

[15] Uçbeyiay, H., \& Özkan, A. (2014). Two-stage shear flocculation for enrichment of fine boron ore containing colemanite. Separation and Purification Technology, 132, 302-308.

[16] Acarkan, N., Kökkılıç, O., Baştürkçü, H., \& Sirkeci, A. A. (2018). Precipitation of boron from waste water of Kirka borax plant. Recycling and Sustainable Development, 11(1), 21-26.

[17] Güngören, C., Özdemir, O., Wang, X., Özkan, Ş. G., \& Miller, J. D. (2019, Apr). Effect of ultrasound on bubbleparticle interaction in quartz-amine flotation system. Ultrasonics Sonochemistry, 52, 446-454.

[18] Özkan, Ş. G. (2018). A review of simultaneous ultrasound-assisted coal flotation. Journal of Mining and Environment, 9(3), 679-689.

[19] Ambedkar, B., Chintala, T. N., Nagarajan, R., \& Jayanti, S. (2011). Feasibility of using ultrasound-assisted process for sulfur and ash removal from coal. Chemical Engineering and Processing: Process Intensification, 50(3), 236-246.

[20] Mason, T. J., Collings, A., \& Sumel, A. (2004). Sonic and ultrasonic removal of chemical contaminants from soil in the laboratory and on a large scale. Ultrasonics Sonochemistry, 11(3-4), 205-210.

[21] Suslick, K. S., Didenko, Y., Fang, M. M., Hyeon, T., Kolbeck, K. J., McNamara III, W. B., ... \& Wong, M. (1999). Acoustic cavitation and its chemical conse- quences. Philosophical Transactions of the Royal Society of London. Series A: Mathematical, Physical and Engineering Sciences, 357(1751), 335-353.

[22] Singh, B. P. (1999). Ultrasonically assisted rapid solidliquid separation of fine clean coal particles. Minerals Engineering, 12(4), 437-443.

[23] Önal, G., Özer, M., \& Arslan, F. (2003). Sedimentation of clay in ultrasonic medium. Minerals Engineering, 16(2), 129-134.

[24] Burat, F., Sirkeci, A. A., \& Önal, G. (2014). Improved fine coal dewatering by ultrasonic pretreatment and dewatering aids. Mineral Processing and Extractive Metallurgy Review, 36(2), 129-135.

[25] Özkul, C., Çiftçi, E., Tokel, S., \& Savaş, M. (2017). Boron as an exploration tool for terrestrial borate deposits: A soil geochemical study in Neogene EmetHisarcık basin where the world largest borate deposits occur (Kütahya-western Turkey). Journal of Geochemical Exploration, 173, 31-51.

[26] Helvacı, C. (2017). Borate deposits: An overview and future forecast with regard to mineral deposits. Journal of Boron, 2(2), 59-70.

[27] Koçak, İ., \& Koç, Ş. (2018). Geochemical characteristics of The Emet (Espey-Hisarcik) borate deposits, Kütahya, Turkey. Journal of African Earth Sciences, 142, 52-63.

[28] Yücel, M. (2018). Bor Atıklarının Çöktürülmesi [Settlement of Boron Tailings]. [B.Sc. Thesis, Istanbul University].

[29] Garip, Ş. (2015). Bor Atıklarının Geri Dönüşümüne Yönelik Karakterizasyon Çalışmaları [Characterization Studies for Recycling of Boron Wastes]. [B.Sc. Thesis, Istanbul University].

[30] Helvacı, C., \& Alonso, R. N. (2000). Borate Deposits of Turkey and Argentina; A Summary and Geological Comparison. Turkish Journal of Earth Sciences, 9(1), 1-27.

[31] Addai-Mensah, J., Yeap, K. Y., \& McFarlane, A. J. (2007). The influential role of pulp chemistry, flocculant structure type and shear rate on dewaterability of kaolinite and smectite clay dispersions under couette Taylor flow conditions. Powder Technology, 179(1-2), 79-83.

[32] Castillo, C., Ihle, C. F., \& Jeldres, R. I. (2019). Chemometric optimisation of a copper sulphide tailings flocculation process in the presence of clays. Minerals, 9(10), 582.

[33] Ye, L., Manning, A. J., \& Hsu, T. J. (2020). Oil-mineral flocculation and settling velocity in saline water. Water Research, 173, 115569.

[34] Ersoy, B., Tosun, İ., Günay, A., \& Dikmen, S. (2009). Turbidity removal from wastewaters of natural stone processing by coagulation/flocculation methods. CLEAN - Soil, Air, Water, 37(3), 225-232.

[35] Arulmathi, P., Jeyaprabha, C., Sivasankar, P., \& Rajkumar, V. (2019). Treatment of textile wastewater by coagulation-flocculation process using gossypium herbaceum and polyaniline coagulants. CLEAN - Soil, Air, Water, 47(7), 1800464.

[36] Karapınar, N. (2019). Flocculation behavior of borax clayey tailings in mono- and dual- flocculant systems: effect of tailings slurry characteristics and polyDAD- 
MAC type. Global Journal of Earth Science and Engineering, 6(1), 9-15.

[37] Birdi, K. S. (2015). Handbook of Surface and Colloid Chemistry. CRC press. ISBN 1466596686.

[38] Kurşun, İ., İpekoğlu, B., Çelik, M. A., \& Kaytaz, Y. (2000). Flocculation and adsorption-desorption mechanism of polymers on albite. In Developments in Mineral Processing (Vol. 13, pp. C5-24). Elsevier.

[39] Winterwerp, J. C. (2002). On the flocculation and settling velocity of estuarine mud. Continental Shelf Research, 22(9), 1339-1360.

[40] Abu Hassan, M. A., Hui, L. S., \& Noor, Z. Z. (2009). Removal of boron from industrial wastewater by chitosan via chemical precipitation. Journal of Chemical and Natural Resources Engineering, 4(1), 1-11.

[41] Weber Jr., W. J. (1972). Physicochemical Processes for $W$ ater Quality Control. John Wiley and Sons. ISBN 0471924350.

[42] Chong, M. F., Lee, K. P., Chieng, H. J., \& Ramli, I. I. S. B. (2009). Removal of boron from ceramic industry wastewater by adsorption-flocculation mechanism using palm oil mill boiler (POMB) bottom ash and polymer. Water Research, 43(13), 3326-3334.

[43] Zarei Mahmudabadi, T., Ebrahimi, A. A., Ehrampoush, M. H., \& Eslami, H. (2021). Investigating the effect of coagulation and flocculation - adsorption process on boron removal from industrial wastewater (Case study: Ceramic tile industry). Journal of Rafsanjan University of Medical Sciences, 19(10), 1015-1034.

[44] Du, J., McLoughlin, R., \& Smart, R. S. C. (2014). Improving thickener bed density by ultrasonic treatment. International Journal of Mineral Processing, 133, 9196.

[45] Zhu, L., Lyu, W., Yang, P., \& Wang, Z. (2020). Effect of ultrasound on the flocculation-sedimentation and thickening of unclassified tailings. Ultrasonics Sonochemistry, 66, 104984

[46] Zhao, Y., Meng, L., \& Shen, X. (2020). Study on ultrasonic-electrochemical treatment for difficult-to-settle slime water. Ultrasonics Sonochemistry, 64, 104978.

[47] Smythe, M. C., \& Wakeman, R. J. (2000). The use of acoustic fields as a filtration and dewatering aid. Ultrasonics, 38(1-8), 657-661.

[48] Kowalski, W., \& Kowalska, E. (1978). The ultrasonic activation of non-polar collectors in the flotation of hydrophobic minerals. Ultrasonics, 16(2), 84-86.

[49] Aldrich, C., \& Feng, D. (1999). Effect of ultrasonic preconditioning of pulp on the flotation of sulphide ores. Minerals Engineering, 12(6), 701-707.

[50] Videla, A., Faúndez, D., Meneses, J., Gaete, L., \& Vargas, Y. (2020). Enhancement of the sedimentation rate of copper tailings by application of acoustic fields. Minerals Engineering, 146, 106096.

[51] de Sarabia, E. R. F., Gallego-Juarez, J. A., RodriguezCorral, G., Elvira-Segura, L., \& Gonzalez-Gomez, I. (2000). Application of high-power ultrasound to enhance fluid/solid particle separation processes. Ultrasonics, 38(1-8), 642-646.

[52] Ambedkar, B., Nagarajan, R., \& Jayanti, S. (2011). Ultrasonic coal-wash for de-sulfurization. Ultrasonics Sonochemistry, 18(3), 718-726.
[53] Özkan, Ş. G., \& Güngören, C. (2012). Enhancement of colemanite flotation by ultrasonic pre-treatment. Physicochemical Problems of Mineral Processing, 48(2), 455-462. 